\title{
Development of numerical model for the determination of crack opening and closure loads, for long cracks.
}

\author{
A. A. Aguilar Espinosa, N. A. Fellows*, J. F. Durodola and L. J. Fellows \\ Department of Mechanical Engineering and Mathematical Sciences, Faculty of \\ Design, Technology and the Environment, Oxford Brookes University, Wheatley \\ Campus, Wheatley, Oxford, OX33 1HX, UK.
}

\begin{abstract}
A two-dimensional Finite Element (FE) model has been developed for determining crack opening and closure stresses, with the eventual aim of investigating plasticity induced closure effects on crack growth under variable amplitude loading. An issue with model verification is obtaining accurate experimental values of crack opening and closure loads. Validation was therefore carried out using experimental data from constant amplitude loading tests, recently obtained by the authors ${ }^{1,2}$ where there was good confidence in the accuracy of the opening and closing loads. Elasticperfect plastic and work hardening material properties were investigated to determine the effect they had on crack growth. The modelling considered long cracks by dividing the crack into consecutive small lengths. For this purpose, the restart capability included in the ABAQUS code was employed. In addition, a mesh refinement strategy was optimised to reduce the memory requirements for the thousands of cycles analysed. This enabled both long crack lengths and small element sizes to be studied which has not been done in the literature before. The FE results were in good agreement with most of the experimental results and possible reasons are given for some of the minor discrepancies observed.
\end{abstract}

KEY WORDS: fatigue; crack growth; finite element; constant amplitude loading; crack closure

\section{Introduction}

There is some controversy with crack closure as a theory for determining crack growth with some researchers believing that crack growth rate is driven by $\mathrm{K}_{\max }$ and $\Delta \mathrm{K}$, as assumed by the "Unified Approach" (UA) theory ${ }^{3}$. Citrella et al. ${ }^{4,5}$ uses the UA to investigate crack growth, in compact tension specimens, plates with inherent residual stresses and stir welded aluminium joints, using the finite element method and dual boundary element method. Other researchers have looked to build on crack closure models to improve on their accuracy. Adedipe et $a l .{ }^{6}$ has for example used the difference in area under the load curve for the crack open portion of the fatigue cycle between a new $\mathrm{R}$ ratio and an $\mathrm{R}$ ratio of 0.1 to predict the crack growth at the new $\mathrm{R}$ ratio. An issue in comparing theories is the difficulty in obtaining appropriate measurements of crack opening and closing ${ }^{7,8}$. The authors have therefore carried out experimental work using an optical technique to obtain measurements of the loads when crack tip opening and closing occurs for 6082-T6 aluminium, subjected to constant amplitude loading and overload and underload cycles ${ }^{2}$. Other issues with comparing crack growth theories have been the lack of sufficiently developed numerical models to validate crack closure ${ }^{9}$ which is related to the issue of inadequacy of the materials models used ${ }^{10}$.

* Correspondence: N. A. Fellows. E-mail: nafellows@brookes.ac.uk 
Ohji et al. ${ }^{11}$ and Ogura and Ohji ${ }^{12}$ developed an FE model to investigate fatigue crack growth using constant strain triangular elements. The model included the effect of kinematic hardening and was used to investigate simple overload and overload/underload cycles. The model though was not used to investigate propagating cracks.

Newman et al. developed a FE model to investigate fatigue crack closure due to cyclic loading ${ }^{13}$. The model was developed to include plasticity, a crack growth criterion and a mixed hardening rule ${ }^{14}$. As Newman admitted, there were shortcomings in the model which were strong dependency on mesh size and the value of the critical strain.

A very different approach was taken by Nakagaki and Atluri ${ }^{15}$ who used a hybrid displacement element to study mixed mode fracture. The crack growth was modelled by moving the "core" singular element a defined distance determined by a crack growth law. The crack growth law incorporated a critical crack extension stress to determine crack growth. A single value for the critical crack extension stress was obtained, though calibration, which prevents the model from being used to model variable loading situations.

Fleck $^{16}$, Fleck and Newman ${ }^{17}$, and Fleck and Shercliff ${ }^{18}$ evolved the FE code developed by Newman ${ }^{14}$ to investigate the effect of plasticity due to overloads on crack retardation under plane strain conditions. The stress intensity factor range $\Delta K$ was kept constant by shedding the load as the crack length increased. Determination of crack growth was not the intention of the authors who focused on crack closure.

McClung and Sehitoglu ${ }^{19,20}$ used a two-dimensional elastic-plastic FE model to examine the behaviour of crack closure. They utilized four-noded isoparametric elements and used the Ziegler kinematic hardening law. Maximum stress, stress ratio and material effects, such as strain hardening and yield strength, were investigated to see what their effect on crack closure was. The study was for constant amplitude loading only.

Borrego et $a .^{21}$ modelled crack closure in MT specimens subjected to overloads and high-low blocks also using a two-dimensional elastic-plastic FE model. In their work similar crack growth response rates between numerical and experimental results were found. Even so they concluded that "further work is required to obtain robust plasticity induced closure prediction".

FE models now seem able to handle the problem more efficiently than analytical models. The work of McClung and Sehitoglu ${ }^{20}$ indicates that numerical models can do as well as analytical models and can also deal with more complex problems involving sophisticated material models, complicated geometries, and large deformations. Three-dimensional FE models have also been used to overcome issues related to thickness when using plane stress and plane strain models ${ }^{22,23}$.

The models presented in literature have shown that the limitations for numerical analysis are the high computational requirements and the difficulty of correctly simulating the contact between the crack flanks. The computational requirements are caused by the need to have high mesh density to capture plasticity generated by the 
crack growth accurately and the desire to model long cracks. In the following sections a finite element model is presented, which utilises mesh optimization and a restart analysis to enable the simulation of long cracks subject to constant amplitude and variable amplitude loading. Comparison is made between the model and constant amplitude load tests.

\section{Numerical procedure}

Material data and experimental tests results have been presented previously by the authors ${ }^{1}$ but some of the data is presented again in this paper for ease of reference.

\subsection{Material properties}

The material selected for study was aluminium alloy 6082 T6 (HE30TF). The elastic material properties used in the model were Young's modulus, E=70 $\mathrm{GPa}$, and Poisson's ratio, $v=0.33$. Four different plasticity cases were initially investigated, as discussed in section 3.1, but the following cyclic hardening rule was eventually selected for the models.

The material properties for cyclic hardening behaviour were obtained by using the Ramberg Osgood relationship shown in Eq. (1). The hardening coefficient $H=443$ $\mathrm{MPa}$ and the hardening exponent $n^{\prime}=0.064$ were obtained from the work carried out by Borrego et al. ${ }^{24,25}$, who performed experimental work with the same 6082-T6 aluminium alloy and reported similar properties for monotonic tensile tests as those obtained by Aguilar Espinosa et al. ${ }^{2}$.

$$
\varepsilon=\frac{\sigma}{E}+\left(\frac{\sigma}{H}\right)^{1 / n^{\prime}}
$$

The yield point was calculated using Eq. (2), and the plastic strain offset $\varepsilon_{p o}$ was considered to be 0.002 , which according to Dowling ${ }^{26}$ is employed generally for engineering calculations.

$$
\sigma_{y}=H(0.002)^{n^{\prime}}
$$

The resulting yield strength was $298 \mathrm{MPa}$, and the input material properties were introduced in a tabular form in the ABAQUS ${ }^{27}$ material module. Antunes et al. ${ }^{28}$ state that aluminium alloy 6082 exhibits both isotropic and kinematic hardening behaviour and investigated the use of a mixed hardening rule for some of their models. In this work an isotropic hardening rule was used, within ABAQUS, based on the work by Gonzalez-Herrera and Zapatero ${ }^{29}$ with the sub option selected of cyclic hardening.

\section{2 Geometry}

The geometry of the model replicated the four-point bending specimens (SENB4) used in the experiments with dimensions $\mathrm{B}=9.52 \mathrm{~mm}, \mathrm{~W}=15.875 \mathrm{~mm}$ and $\mathrm{L}=200 \mathrm{~mm}$ with initial notch length, $\mathrm{M}$, set to $1.25 \mathrm{~mm}$. To reduce computation time, just one half of the specimen was modelled using symmetry conditions. The dimensions of the 
specimens are illustrated in Fig. 1 and the model boundary conditions are shown in Fig. 2.

\subsection{Crack faces contact}

The contact between crack flanks has been simulated by several authors and a good review of these methods was made by Solanki ${ }^{30}$. In his work he stated that contact can be achieved by changing the stiffness of spring elements attached to the crack surface by removing or imposing crack closure nodal constraints, by using truss elements on the crack surface or by using contact elements.

With the current capabilities of commercial FE codes, the contact interaction can be modelled. ABAQUS has the capability to simulate contact between a master and a slave surface with a corresponding interaction property. The contact of the crack flanks was therefore simulated by introducing a constrained rigid line at the symmetry boundary position. In this case the crack face was modelled as the slave and the rigid line as a master. ABAQUS has an interaction property to simulate hard contact with two different options. According to ABAQUS, when two surfaces are in contact pressure can be transmitted between them. The surfaces separate if the contact pressure reduces to zero and separated surfaces come into contact when the clearance between them reduces to zero. Currently two methods of constraint enforcement can be used in ABAQUS/Standard; the classical Lagrange multiplier method and the augmented Lagrange method. Both methods can be used to simulate the contact so they were compared in a simple constant amplitude simulation and it was found that the augmented Lagrange method is faster and produces a maximum penetration of the order $10^{-13} \mathrm{~m}$. For these reasons the augmented Lagrange method was employed.

The augmented Lagrange method uses a penalty function during each iteration. Iterations continue until convergence in the solution is obtained with the penalty method. If the slave node penetrates the master surface by more than $0.1 \%$ of the characteristic interface length, the contact pressure is augmented, and another series of iterations are executed until convergence is once again achieved. Only when the penetration tolerance requirement is satisfied, is the solution achieved. This option cannot be used in conjunction with the debond option included in ABAQUS, which instead, uses a fracture criterion that must be satisfied in order to debond the two, previously determined, surfaces.

\subsection{Element type}

The element type used for all the FEM simulations was a CPS4R, which is a four node bilinear plane stress quadrilateral element of first order. Quadrilateral elements have been used by other authors ${ }^{31-34}$ and they have reported good results when using first order elements. Borrego et al. ${ }^{21}$ used plane stress elements due to issues of racheting and mesh dependency when utilising linear kinematic hardening with plane strain elements based on the principle that the plane stress conditions at the surface of 3D bodies will dominate regardless of specimen thickness. In this work, although the specimens are thicker than those used by Borrego et $a .^{21}$, planes stress conditions were also assumed as the experimental crack closure opening and closure load values were measured at the surface. 
In order to reduce running time, the reduced integration option was employed, which means that only one integration point per element is present. Also ABAQUS ${ }^{27}$ includes an hourglass control to avoid excessive distortion of the elements, which was employed during the analysis.

\subsection{Mesh and Element Size}

The meshing scheme to simulate constant amplitude load has been studied by several authors. The element size is a key issue in the model in order to produce correct plastic zone sizes. This can be achieved by employing very small size elements but this is computationally expensive. During crack propagation under mode I two different types of plastic zones are generated; reverse and forward plastic zones. Fig. 3 shows the plastic deformation around the crack tip, the forward plastic zone is the material near the crack tip undergoing plastic tensile deformation at maximum load and the reversed plastic zone is the material near the crack tip undergoing plastic compressive yielding at the minimum load. The plastic wake is created as the crack advances. This plasticity must be generated accurately in the finite element model in order to accurately account for effects of plasticity induced crack closure.

Some studies have been carried out to select the minimum element size to produce a proper representation of the plastic zone. The most commonly used criteria is based on McClung analysis ${ }^{19}$. In this work it was stated that the mesh refinement should be based on the length of the forward plastic zone along the crack plane denoted as $r_{p}$ in Eq. (3) and Eq. (4) from Irwin ${ }^{35}$.

$$
\begin{aligned}
& r_{p}=\frac{1}{\pi}\left(\frac{K_{I}}{\sigma_{y}}\right)^{2} \text { For plane stress } \\
& r_{p}=\frac{1}{3 \pi}\left(\frac{K_{I}}{\sigma_{y}}\right)^{2} \text { For plane strain }
\end{aligned}
$$

Once the plastic zone is calculated it is necessary to know the number of elements that should be within the reverse and forward plastic zones. The mesh selected has to be fine enough to capture both reverse and forward plastic zones.

\subsubsection{Minimum number of elements in the forward plastic zone $\left(r_{p}\right)$}

There is a criteria proposed by McClung ${ }^{19}$ for the number of elements present in the forward plastic zone in order to capture the near-tip strain intensification for quadrilateral elements (Q4). These criteria estimate the width of the forward plastic zone size along a crack line at maximum load according to a simple Irwin-type relationship for centre-cracked panels under plane stress. Eq. (5) shows the relationship between the forward plastic zone size $\left(r_{p}\right)$ and the crack length a. McClung recommended a value of $\Delta a / r_{p} \leq 0.05$ for triangular elements and $\Delta a / r_{p} \leq$ 0.10 for Q4 elements, when $R=0$. The numerical crack increment is denoted as $\Delta a$; which refers to the minimum element size. 


$$
\frac{r_{p}}{\Delta a}=\left(\frac{S_{\max }}{\sigma_{0}}\right)^{2}
$$

Several researchers ${ }^{29}, 32,34,36,37$ have employed the criterion proposed by McClung and have reported good results in the simulation of crack growth.

\subsubsection{Minimum number of elements in the reversed plastic zone (ry)}

One more important aspect of the plastic zone size is reversed plasticity. The reversed or cyclic plastic zone size for a stationary crack is four times smaller than the comparable monotonic value ${ }^{38}$, see Fig. 4 . As the nominal tensile load is reduced, the plastic region near the crack tip is put into compression by the surrounding elastic body. Eqs. (3) and (4) become Eqs. (6) and (7) to represent the reverse plastic zone, $r_{y}$. The reverse plastic zone size has been shown to be small and tend towards the approximation for the plane strain state, Eq. (7), even in thin plates (where plane stress should dominate). Thus LEFM concepts can often be used in the analysis of fatigue crack growth problems even in materials that exhibit considerable amounts of ductility as the basic assumption that the plastic zone size is small in relationship to the crack and the cracked body usually remains valid ${ }^{39}$.

$$
\begin{aligned}
& \mathrm{r}_{\mathrm{y}}=\frac{1}{4 \pi}\left(\frac{K_{I}}{\sigma_{y}}\right)^{2} \text { For plane stress } \\
& \mathrm{r}_{\mathrm{y}}=\frac{1}{12 \pi}\left(\frac{K_{I}}{\sigma_{y}}\right)^{2} \text { For plane strain }
\end{aligned}
$$

According to Solanki et al. ${ }^{30,31}$ the number of elements in the reverse plastic zone should be at least 3 to 4 . Other authors ${ }^{34,40}$ have followed this suggestion and have reported good results.

\subsubsection{Mesh refinement and optimization}

One of the principal problems when simulating fatigue crack closure is the need for significant computing capabilities and the amount of running time that a solution takes. The crack lengths that can be simulated are limited in proportion to the element size. For constant amplitude load this is not a significant problem, because once the crack reaches the steady state the $\sigma_{o p}$ and $\sigma_{c l}$ values remain relatively constant for the whole crack, with a small increasing tendency, where normalized opening levels are plotted against normalized crack length ${ }^{19,29,32,34}$. When symmetry conditions apply in the modelling of crack closure, a solution to optimizing the cost of computing is simulating half or quarter specimen geometries and also utilising mesh reduction as shown in Fig. 5. Utilising the linear option with multi-point constraints, within ABAQUS $^{27}$, linearly constrains non-aligned nodes, between a high density mesh and low density that met along an edge, to the aligned nodes on that edge. This enables mesh reduction to be carried out with minimal mesh distortion. 
For later models the tie constraint capability in $\mathrm{ABAQUS}^{27}$, which enables surfaces with differing amount on nodes to be tied together, was utilised rather than multipoint constraints. Two constraint enforcement methods (Lagrange multiplier and augmented Lagrange), which try to prevent penetration between surfaces, were used to compare their effectiveness and effect on solution speed.

Up to now the ability to simulate long cracks has been restricted by the element size and by the large amount of steps required to propagate the crack ${ }^{9}, 12,16,29,31,32,34,36,37$, 41-43. The maximum length found in the literature is about $4.584 \mathrm{~mm}$ employing 100 $\mu \mathrm{m}$ element size $^{41}$, which represents a large element size when simulating variable amplitude loading. The smallest element found for crack growth simulation was estimated to be $0.5 \mu \mathrm{m}$ from the work by Tarantino et al. ${ }^{44}$, but this was for micro specimens which had very short crack lengths.

In this work several different element sizes have been used with mesh refinement to examine their effect on the prediction of crack opening and closing stresses (in light of the recommendations given by other authors as discussed in sections 2.5.1 and 2.5.2). The largest element size was based on the distance at which the crack growth rate $d a / d N$ was measured experimentally ${ }^{2}$, which corresponded to $125 \mu \mathrm{m}$. The mesh size was then reduced in steps $(125 / 2,62.5 / 2$, etc), halving the mesh size each time to the minimum element size used of $3.90625 \mu \mathrm{m}$. This minimum value was selected as it was seen in SEM pictures of failed specimens ${ }^{2}$ that crack jumps of approximately 510 microns occurred after overloads. Therefore, to capture the opening and closure loads immediately following an overload it would be necessary for the node distance along the crack to be less than $5 \mu \mathrm{m}$.

\subsubsection{Size of crack tip plastic zone and applicability of LEFM}

The plastic zone generated by numerical analysis should ideally be identical to that generated experimentally. The yield criterion used in ABAQUS is that the material deforms plastically when the Von Mises stress reaches the yield stress value. The Von Mises yield criterion states that yielding will occur when:

$$
2 \sigma_{y}^{2}=\left(\sigma_{1}-\sigma_{2}\right)^{2}+\left(\sigma_{2}-\sigma_{3}\right)^{2}+\left(\sigma_{3}-\sigma_{1}\right)^{2}
$$

In the case of mode I load, the stress field equations for a two-dimensional principal stresses case, are given by Eq. (9) and Eq. (10)

$$
\begin{aligned}
& \sigma_{1}=\frac{K_{I}}{\sqrt{2 \pi r}} \cos \frac{\theta}{2}\left(1+\sin \frac{\theta}{2}\right) \\
& \sigma_{2}=\frac{K_{I}}{\sqrt{2 \pi r}} \cos \frac{\theta}{2}\left(1-\sin \frac{\theta}{2}\right)
\end{aligned}
$$

where $\sigma_{3}$ is either zero (plane stress) or $v\left(\sigma_{1}+\sigma_{2}\right)$ for plane strain. Substitution into Eq. (8) gives for plane stress

$$
2 \sigma_{y}^{2}=\frac{K_{I}^{2}}{2 \pi r}\left(1+\frac{3}{2} \sin ^{2} \theta+\cos \theta\right)
$$


The application of LEFM has a limitation on the size of the plastic zone. If the plastic zone is small enough, there will be a region outside of it where the elastic stress field equations still apply, called the region of $K$-dominance ${ }^{26}$. Thus, $K$ continues to characterize the severity of the crack situation, despite the occurrence of some limited plasticity. Fig. 6, illustrates the $K$-field area where LEFM applies.

The plastic zone size for plane stress under monotonic load is represented in Fig. 7. Linear elastic fracture mechanics (LEFM) specify that the plastic zone must be small compared with the distance from the crack tip to any boundary of the member. Eq. (12), states the criteria for the specimen dimensions, see Fig. 8, for the plastic zone $r_{p}$ to be within LEFM. The experimental tests ${ }^{2}$ that are being replicated by the numerical models meet this criterion.

$$
4 r_{p} \leq \mathrm{a},(\mathrm{b}-\mathrm{a}), \mathrm{h}
$$

\subsection{Restart option}

Initial simulations to grow the crack by $4 \mathrm{~mm}$ with a $3.9 \mu \mathrm{m}$ element size resulted in long model run times and made post processing difficult due to the large result files. All simulations were carried out on a standard PC with 4 GB RAM of memory and a $3.0 \mathrm{GHz}$ speed Intel Core Duo E8400 processor. Current computing capabilities allows longer crack models to be run, however this does not resolve the issue of generating large files (>100 GB). To overcome this issue the restart capability was used within ABAQUS ${ }^{27}$ which gives the ability to run models with long crack growth, utilising low frequency processors (such as used in laptops) and minimising post processing data, through the discretisation of the crack growth into separate model files.

The restart option divides up the number of steps within the model into sets and generates an input file for each set. These sets can then be run sequentially with information from one set being fed into the following set. This provides an important improvement in memory storage during running of the model and during post processing analysis, as the results data can be analysed separately.

For the constant amplitude load using the smallest element size 4094 steps were required. Every input file was divided into approximately 200 steps, which generated an output file around 3.6 GB. The number of steps per input file was decided on to facilitate the management and storage of the files. Bigger output files are more difficult to handle and to manipulate for post processing analysis. In total 20 input files were generated to simulate the $4 \mathrm{~mm}$ of crack growth for all load cases.

\subsection{Modelling of crack growth}

To accurately model crack growth a detailed knowledge of the microscopic phenomena that occurs is necessary ${ }^{45}$. In this work stage II type I crack opening is examined, where nominally the crack grows in a direction macroscopically perpendicular to the main principal stress. During stage II the crack growth is independent of microstructural effects and crack closure models can be applied. 
In real conditions the crack follows an irregular path line as illustrated in Fig. 9(a) and Fig. 9(b), however within the developed finite element model the crack was predefined as a straight path without any irregularity in its trajectory, as it is illustrated in Fig. 9(c) and Fig. 9(d), which correspond to the FEM simulation. This is one of the limitations with numerical modelling. However some analysis has been carried out to model plasticity and roughness induced crack closure such as Parry et al.'s model ${ }^{46}$. In that work a $2 \mathrm{D}$ model was created to study the effect of crack deflection and prior plastic deformation under constant amplitude load for a $100 \mu \mathrm{m}$ crack length simulation. The results showed that the closure levels increase strongly with the deflection angle, which is closer to the real conditions. Nevertheless, the modelling is not simple and exhaustive work is required to model simple variable amplitude loading in 2D analysis. Ideally due to the irregular crack flanks 3D modelling is required but this would be a highly complex task. Currently issues exist with regard to the release node scheme along the crack tip front line and the appropriate mesh to employ.

Another issue that does not correspond to real situations is the crack increment $\Delta a$ used per number of cycles. This issue is discussed in light of the results in section 3.2.

Two dimensional analysis for plasticity induced crack closure has been carried out by some authors for constant amplitude load with some applications of block and single overloads ${ }^{10,14,47}$ and they have reported acceptable results when modelling cracks with a straight path. Based on this work, the present study employs a straight line to model plasticity induced crack closure.

\subsection{Crack growth scheme}

The crack advance simulation was performed by the release node technique; thus the boundary conditions for each node ahead of the crack tip were released periodically every two cycles, hence the increment $\Delta a_{i}$ of the crack is equal to the element size. The point in the load cycle where the node is released has been discussed by several researchers, but until now no general agreement has been postulated as to the correct one. Some authors release the node at minimum load ${ }^{12,34,48}$ to avoid convergence problems. Others have suggested advancing the crack at maximum load, arguing that the crack growth occurs at maximum load ${ }^{16,30-33,40,43,46}$. In this work the crack extension was carried out immediately after maximum load which is in accordance with several works ${ }^{19,20,49-51}$.

\subsection{Measurement of crack opening stresses}

The opening stress and closure stress is defined as the stress value, during a loading cycle, when the crack flanks open fully (no contact between crack flanks) or just start to close (initial contact between crack flanks). In the numerical model the first node behind the crack tip was monitored to find the exact moment it changed from a zero to a positive displacement during the loading stage as the measure of the crack being completely open (or vice versa for closure). This method has been used by several authors $^{16,19,20}$ to extract the opening values. Some authors ${ }^{30,31}$ have though argued that the first node should not be used to monitor the opening stress as a result of the high stress concentration that makes the information unreliable. The contact pressure 
between crack surfaces was therefore also monitored to detect the instant when it became completely zero.

\subsection{Time increments to apply the loads}

ABAQUS can automatically determine the number of increments in which to subdivide the load, however some authors ${ }^{29,34}$ mention that this parameter has some influence on the values of the opening stresses. In this work intervals from 1/32 to $1 / 40$ were used for the opening load cycle and from $1 / 19$ to $1 / 40$ for the closure load cycle. The results (see section 3.4) showed no significant difference between the number of time increments, hence the maximum increment size was used to reduce computational time.

\section{Results and discussion}

\subsection{Material properties}

The correct use of material properties in numerical simulations has a significant effect due to the plasticity generated at the crack tip. Some researchers have used elasticperfect plastic behaviour for the simulation of aluminium, as some aluminium alloys tend to exhibit elastic-perfect plastic behaviour. In this work comparison was made between using an elastic perfect plastic rule, two bilinear hardening rules $(\mathrm{H} / \mathrm{E}=0.0138$ and $\mathrm{H} / \mathrm{E}=0.00869)$ and a cyclic hardening rule (see section 2.1). It was seen that the cyclic and bilinear hardening properties gave higher opening and closing stress values, which were closer to the experimental data. The choice of using isotropic hardening is discussed in more detail in section 3.5.

\subsection{Effect of element size on plastic zone and crack opening and closure stresses}

In Table 1, the elements that have yielded, using a von Mises criterion, in front of the crack tip are presented for varying minimum element sizes.

The highlighted values in the table correspond to values that meet the convergence criteria suggested by McClung et al. ${ }^{19}$ that $\Delta a / r_{p} \leq 0.1$ (for quadrilateral elements and $\mathrm{R}=0$ ). It can be seen that a minimum size of $7.8 \mu \mathrm{m}$ would be required to meet the criteria but that an element length of $15.6 \mu \mathrm{m}$ would be appropriate apart for very short crack lengths.

The opening and closure stresses for different element sizes are shown in Fig. 10.

It can be seen that as the element size drops below $15 \mu \mathrm{m}$ the opening and closure stresses start to converge at medium to high crack lengths. The convergence for the opening stresses correlates well with the results of McClung et al. and indicates that an element size of $15 \mu \mathrm{m}$ should give good stress opening values for constant amplitude loading. For closure stresses the crack lengths at which convergence happens is much later than from the McClung et al. criteria and smaller element sizes would be needed to obtain convergence at the shorter crack lengths. It was seen experimentally ${ }^{2}$ that crack jumps as small as $5 \mu \mathrm{m}$ occur when applying overloads. 
For the model utilising $3.9 \mu \mathrm{m}$ size elements along the crack path, 1024 nodes had to be released to grow the crack $4 \mathrm{~mm}(5.25 \mathrm{~mm}$ crack length as initial notch is $1.25 \mathrm{~mm}$ deep) with an increment of $3.9 \mu \mathrm{m}$ for every two numerical load cycles (see section 2.8). The experimental crack growth was $0.11 \mu \mathrm{m} /$ cycle. Therefore, there are 35.5 real increments (35.5 load cycles) for every 1 simulated increment ( 2 numerical load cycles). It is possible to model extremely small element sizes, $<0.1 \mu \mathrm{m}$, but this would significantly increase the computational run time to grow a $4 \mathrm{~mm}$ crack, as well as the corresponding analysis time. This must be weighed against the increase in accuracy obtained and as can be seen in figure 10, for constant amplitude loading, the opening and closure stresses have converged by the time the element size reaches $3.9 \mu \mathrm{m}$.

Normal reduction and reduction using tie restraints were carried out but no discernible difference in results was found between the opening and closure values. Also the forward plastic zone size was similar for both cases. The augmented Lagrange constraint method produced slightly smaller penetrations levels than multiplier Lagrange method and gave solution times that were about six times faster.

\subsection{Comparison of analytical and numerical plastic zone sizes.}

The plastic zone size $r_{p}$ in Table 2 shows the values obtained using the Irwin approximation. The values obtained using an FE model utilising a minimum element size of $3.9 \mu \mathrm{m}$ with the Von Mises criterion, are compared in Fig 11. The size of the plastic zone given by the FE model was obtained by counting the failed elements ahead of the crack tip $\left(\sigma>\sigma_{y}\right)$. It can be seen that the plastic zone simulated by the FE model is smaller than the one calculated by the Irwin approximation for plane stress, Eq. (3). The results are though close and it would be expected that the Irwin approximation which assumes elastic perfectly plastic conditions would be higher than the numerical model that assumes material hardening occurs.

In Fig. 12, the size of the reverse plastic zone is shown. The FE simulations fall between the approximations for plane stress and plain strain, Eq. (5) and Eq. (6). It was expected that the reverse plasticity zone size would be closer to the plain strain condition even when the loading is close to plane stress, see section 2.5.2.

One possible cause for the smaller plastic zone size from the FE model is due to the number of cycles applied between the releasing of each node. One recent study ${ }^{34}$ addressed the issue of the number of cycles between node release. In that work it was pointed out that for plane strain there is a strong dependence between the opening stress level and the number of load cycles, in addition for plane stress it was reported that 2 cycles between node releases gave more consistent results than single load cycles.

In order to assess the effect that the amount of load cycles between node releases has models were run where nodes were released every load cycle or every other load cycle. As can be seen in Fig 13, this does not seem to affect the opening and closing stress values determined. Models with more load cycles per node release were not run due to time restrictions. 
The measurement of the opening loads due to node separation behind the crack tip should be reliable because it directly monitors the time of separation of the node within the load cycle. There is though some dispute over how accurate this is hence results were compared against the contact pressure in the first node behind the crack tip and the time load increment values were the same for both methods.

\subsection{The effect of load time increments on opening and closing stress values.}

In Fig. 14, the opening and closure stress values utilising different load time increments are presented for a $15 \mu \mathrm{m}$ element size. The variation in load time increment size will clearly have some effect on the opening and closing loads measured due to the discretisation of the load. The results though showed no significant variation on the determined opening and closing stress values.

\subsection{Comparison with experimental crack opening and closing loads}

The experimental results for normalised crack opening stresses and closure stresses are presented in Fig. $10^{1,2}$. As can be seen the normalised opening stresses rise from approximately 0.67 to 0.73 and the closure stress from 0.6 to 0.65 . It is expected that the experimental opening and closure loads would be similar but there can be differences as stated by Schijve ${ }^{52}$. In Fig. 10 it can be seen that numerically the normalised opening stresses rise to approximately 0.62 and the normalised closure stresses rise to approximately 0.5 for the $3.9 \mu \mathrm{m}$ element size. The predicted normalised closure and opening stresses are therefore significantly smaller than the experimental results but follow the same trend in that the closure stresses are lower than the opening stresses.

There could be several factors that account for this such as load discretisation, difficulty in accurately measuring the crack opening and closing experimentally, under estimation of the plastic zone, and the surface roughness not being taken into account in the model. The assumption of plane stress conditions is not the cause of the discrepancy as this would increase the crack closure loads, due to increased plasticity at the crack tip.

An issue when comparing numerical and experimental results is the inherent error that exists with experimental data. The optical method selected by the authors ${ }^{2}$ was selected to minimise the error but none the less the method requires some user interpretation in terms of the point the crack is open and closed. Full field displacement techniques such as moiré interferometry, which can give high resolution measurements of crack opening, have been used but it is an experimentally complex method with many drawbacks ${ }^{53}$. Digital Image Correlation has similar benefits to moiré interferometry, has the advantage of 3D measurement and is relatively much easier to apply. Due to this, it is becoming more widely used, which should lead to more accurate experimental data ${ }^{45,53,54}$.

Although there is some error generated due to load discretisation it should be small and the major error is more likely due to not correctly modelling the amount of plasticity and its distribution. In real situations the plastic zone is likely to be larger and more uniform because it is created every cycle. In the numerical analysis the load 
is only applied at $\Delta \mathrm{a}$ increments, which creates wider gaps between the plasticity generated, leading to smaller plastic zones and lower closure values.

An aspect that was not investigated in this work is the effect of changing the material model to incorporate kinematic hardening. Antunes et al. ${ }^{28}$ obtained results from middle tension specimen numerical models, using small crack tip elements, that showed that kinematic hardening decreased the crack opening loads. This would indicate that using kinematic hardening would cause a larger discrepancy in our case with the experimental results. They did though also show a model dependency in terms of element size and the material hardening model.

The surface roughness of the crack is also likely to have a significant effect on the distribution of the plasticity generated behind the crack tip.

\subsection{Comparison of numerical and experimental crack growth prediction}

Fig. 15 shows the fitting of crack growth versus length data using the Paris $\mathrm{Law}^{55}$ and Elber's equation ${ }^{56}$ (utilising numerical opening and closure load data) for one experimental test. In the Elber equation the $\mathrm{K}_{\text {eff }}$ (effective stress intensity) was calculated by taking the average $\mathrm{K}_{\mathrm{op}}$ and $\mathrm{K}_{\mathrm{cl}}$ values (numerically obtained) from the $\mathrm{K}_{\max }$ value. As the value of the fitting parameter $\mathrm{m}$ is similar for both methods this would seem to indicate that the percentage underestimation of the numerical crack opening and closing stress loads relative to the max load applied, see section 3.5 , is constant. The constant percentage difference generated between the stress intensities for each method is accommodated, when fitting, by the $\mathrm{C}$ value (scaling factor) to give similar crack growth predictions.

\section{Conclusions}

Fatigue crack propagation was carried out with FEM using a two-dimensional plane stress elastic-plastic model and compared with experimental results for four-point bend specimens ${ }^{1,2}$.

The release node technique was used to advance the crack, after every load cycle or every other load cycle. Very little difference was found in the opening or closure stresses measured between the two methods for constant amplitude loading.

The opening stresses were measured by monitoring the step time when the displacement at the first node behind the crack tip became positive during the second load cycle. The point at which the contact pressure, at the same node, became zero was also measured. Both methods gave the same results for the opening stress.

Two constraint enforcement methods were compared and the results showed a minimum penetration in both cases. The augmented Lagrange method was preferred to the multiplier Lagrange method as it produced a smaller amount of allowable penetration and gave solution times that were approximately six times faster.

In line with the work of McClung ${ }^{18}$, it was found that the smaller the element size the larger the numerical prediction was for the plastic zone. Even so, when using the smallest minimum element size of $3.91 \mu \mathrm{m}$ the monotonic plastic zone $r_{p}$ was smaller 
from the ABAQUS model than predicted by the Irwin approximation for plane stress. A difference in results is expected though as the Irwin approximation assumes elastic perfectly plastic conditions whereas the numerical model assumes material hardening occurs. The assumed plane stress condition in the model would increase plasticity at the crack tip and is therefore not the cause. Another explanation is that the numerical model is under predicting the plastic zone size.

The lower numerical crack opening and closure results compared with the experimentally measured results would support this contention. The authors believe the most probably causes of the difference in results are due to the model not capturing the real material plastic behaviour ${ }^{10}$, a non-realistic plastic distribution in the model due to load cycle discretisation along the crack path and an incorrect distribution of the plasticity behind the crack tip due to surface roughness. Kinematic hardening was not considered in this work but kinematic hardening would likely generate a larger error in the results, as Antunes et $a l .{ }^{28}$ have shown that kinematic hardening reduces the crack opening loads.

Although the experimental method employed by the authors ${ }^{2}$ was selected to minimise errors in crack opening load measurements, techniques such as DIC have the potential to significantly improve experimental accuracy.

The experimental Paris ${ }^{55}$ and the numerical Elber ${ }^{56}$ fits for constant amplitude loading both give good predictions of crack growth showing that the percentage difference between the stress intensity values used in the methods is remaining constant.

The restart capability within ABAQUS and mesh refinement techniques were utilised to reduce post processing requirements. These techniques allow long crack lengths to be modelled with high mesh density enabling future models to be developed to investigate variable amplitude loading up to failure with high enough element resolution to give better predictions of crack growth using crack closure theory.

\section{ACKNOWLEGMENTS}

The authors would like to thank CONACYT, Mexico, for supporting the work through the provision of a PhD scholarship (Ref: 195606)

\section{REFRENCES}

1. Aguilar-Espinosa AA (2009) Effect of variable amplitude loading on fatigue crack growth rate [electronic resource]. Oxford Brookes University, Oxford.

2. Aguilar-Espinosa AA, Fellows NA, Durodola JF (2013) Experimental measurement of crack opening and closure loads for 6082-T6 aluminium subjected to periodic single and block overloads and underloads. International Journal of Fatigue. 47: 71-82.

3. Bukkapatnam STS, Sadananda K (2005) A generic algorithm for unified approach-based predictive modeling of fatigue crack growth. International Journal of Fatigue 27: 1354-1359.

4. Citarella R, Cricrì G (2009) A two-parameter model for crack growth simulation by combined FEM-DBEM approach. Advances in Engineering Software. 40: 363-377. 
5. Citarella RC, P.; Sepe, R.; Lepore, M. (2016) DBEM crack propagation in friction stir welded aluminum joints. Advances in Engineering Software

6. Adedipe O, Brennan F, Kolios A (2016) A relative crack opening time correlation for corrosion fatigue crack growth in offshore structures. Fatigue \& Fracture of Engineering Materials \& Structures. 39: 395-411.

7. Shorupa M (1999) Load interaction effects during fatigue crack growth under variable amplitude loading - A literature review. Part I: Empirical trends (vol 21, pg 987, 1998). Fatigue \& Fracture of Engineering Materials \& Structures. 22: $926-926$.

8. Skorupa M (1999) Load interaction effects during fatigue crack growth under variable amplitude loading - a literature review. Part II: qualitative interpretation. Fatigue \& Fracture of Engineering Materials \& Structures. 22: 905-926.

9. Antunes FV, Rodrigues DM (2008) Numerical simulation of plasticity induced crack closure: Identification and discussion of parameters. Engineering Fracture Mechanics. 75: 3101-3120.

10. Pommier S (2003) Cyclic plasticity and variable amplitude fatigue. International Journal of Fatigue. 25: 983-997.

11. Ohji K, Ogura K, Ohkubo Y (1975) Cyclic analysis of a propagating crack and its correlation with fatigue crack growth. Engineering Fracture Mechanics. 7: 457-463.

12. Ogura K, Ohji K (1977) FEM ANALYSIS OF CRACK CLOSURE AND DELAY EFFECT IN FATIGUE CRACK GROWTH UNDER VARIABLE AMPLITUDE LOADING. Engineering Fracture Mechanics. 9: 471-480.

13. Newman JC, Armen H (1975) ELASTIC-PLASTIC ANALYSIS OF A PROPAGATING CRACK UNDER CYCLIC LOADING. Aiaa Journal. 13: 1017-1023.

14. Newman JC (1977) Finite element analysis of crack growth under monotonic and cyclic loading. American Society of Testing Materials, 56-80.

15. Nakagaki M, Atluri SN (1980) ELASTIC-PLASTIC ANALYSIS OF FATIGUE CRACK CLOSURE IN MODES I AND II. Aiaa Journal. 18: 1110-1117.

16. Fleck NA (1986) FINITE-ELEMENT ANALYSIS OF PLASTICITYINDUCED CRACK CLOSURE UNDER PLANE-STRAIN CONDITIONS. Engineering Fracture Mechanics. 25: 441-449.

17. Fleck NA, Newman JC (1988) Analysis of crack closure under plain strain conditions. Mechanics of fatigue crack closure. American Society of Testing Materials, 319-341.

18. Fleck NA, Shercliff HR (1989) Overload retardation due to plasticity induced crack closure. 7th International Conference of Fracture. Pergamon Press, Houston, TX; United States, 1405-1415.

19. McClung RC, Sehitoglu H (1989) ON THE FINITE-ELEMENT ANALYSIS OF FATIGUE CRACK CLOSURE .1. BASIC MODELING ISSUES. Engineering Fracture Mechanics. 33: 237-252.

20. McClung RC, Sehitoglu H (1989) ON THE FINITE-ELEMENT ANALYSIS OF FATIGUE CRACK CLOSURE .2. NUMERICAL RESULTS. Engineering Fracture Mechanics. 33: 253-272.

21. Borrego LP, Antunes FV, Costa JD, Ferreira JM (2012) Numerical simulation of plasticity induced crack closure under overloads and high-low blocks. Engineering Fracture Mechanics. 95: 57-71. 
22. Chermahini RG, Shivakumar KN, Newman JC (1989) Three dimensional finite element simulation of fatigue crack growth and closure. Mechanics of fatigue crack closure. edn. American Society of Testing Materials, 398-413.

23. de Matos PFP, Nowell D (2008) Numerical simulation of plasticity-induced fatigue crack closure with emphasis on the crack growth scheme: $2 \mathrm{D}$ and 3D analyses. Engineering Fracture Mechanics. 75: 2087-2114.

24. Borrego LP, Abreu LM, Costa JM, Ferreira JM (2004) Analysis of low cycle fatigue in AlMgSi aluminium alloys. Engineering Failure Analysis. 11: 715725.

25. Borrego LP, Ferreira JM, Costa M (2008) Partial crack closure under block loading. International Journal of Fatigue. 30: 1787-1796.

26. Dowling NE (2006) Mechanical behaviour of materials, engineering methods for deformation, fracture and fatigue. Prentice Hall, Blacksburg, Virginia.

27. (2004) ABAQUS/Standard User's Manual. Hibbit, Karlsson \& Sorensen Inc, Pawtucket, RI, USA.

28. Antunes FV, Borrego LFP, Costa JD, Ferreira JM (2004) A numerical study of fatigue crack closure induced by plasticity. Fatigue \& Fracture of Engineering Materials \& Structures. 27: 825-835.

29. Gonzalez-Herrera A, Zapatero J (2005) Influence of minimum element size to determine crack closure stress by the finite element method. Engineering Fracture Mechanics. 72: 337-355.

30. Solanki K, Daniewicz SR, Newman JC (2004) Finite element analysis of plasticity-induced fatigue crack closure: an overview. Engineering Fracture Mechanics. 71: 149-171.

31. Solanki K, Daniewicz SR, Newman JC (2003) Finite element modeling of plasticity-induced crack closure with emphasis on geometry and mesh refinement effects. Engineering Fracture Mechanics. 70: 1475-1489.

32. Wei LW, James MN (2004) Numerical modelling of plasticity-induced crack closure for interfacial cracks in bi-material specimens. Engineering Fracture Mechanics. 71: 309-327.

33. Jiang YY, Feng ML, Ding F (2005) A reexamination of plasticity-induced crack closure in fatigue crack propagation. International Journal of Plasticity. 21: $1720-1740$.

34. de Matos PFP, Nowell D (2007) On the accurate assessment of crack opening and closing stresses in plasticity-induced fatigue crack closure problems. Engineering Fracture Mechanics. 74: 1579-1601.

35. Irwin GR (1960) Plastic zone near a crack and fracture toughness. Seventh Sagamore Ordnance Materials Research Conference on Mechanics and Metals Behaviour of Sheet Material. Syracuse University, Racquette Lake, New York, 463-478.

36. Alizadeh H, Simandjuntak S, Smith D, Pavier M (2007) Prediction of fatigue crack growth rates using crack closure finite element analysis. International Journal of Fatigue. 29: 1711-1715.

37. Zapatero J, Moreno B, Gonzalez-Herrera A (2008) Fatigue crack closure determination by means of finite element analysis. Engineering Fracture Mechanics. 75: 41-57.

38. Rice JR (1967) Mechanics of crack tip deformation and extension by fatigue. Fatigue Crack Propagation. American Society of Testing Materials.

39. Bannantine JA, Comer JJ, Handrock JL (1990) Fundamentals of metal fatigue analysis. Prentice Hall, Englewood Cliffs, N.J., xiii, 273 p. 
40. Skinner JD, Daniewicz SR (2002) Simulation of plasticity-induced fatigue crack closure in part-through cracked geometries using finite element analysis. Engineering Fracture Mechanics. 69: 1-11.

41. Lei Y (2008) Finite element crack closure analysis of a compact tension specimen. International Journal of Fatigue. 30: 21-31.

42. Wei LW, James MN (2000) A study of fatigue crack closure in polycarbonate CT specimens. Engineering Fracture Mechanics. 66: 223-242.

43. Sander M, Richard HA (2006) Fatigue crack growth under variable amplitude loading - Part II: analytical and numerical investigations. Fatigue \& Fracture of Engineering Materials \& Structures. 29: 303-319.

44. Tarantino MG, Beretta S, Foletti S, Papadopoulos I (2013) Experiments under pure shear and rolling contact fatigue conditions: Competition between tensile and shear mode crack growth. International Journal of Fatigue. 46: 67-80.

45. Chowdhury P, Sehitoglu H (2016) Mechanisms of fatigue crack growth - a critical digest of theoretical developments. Fatigue \& Fracture of Engineering Materials \& Structures. 39: 652-674.

46. Parry MR, Syngellakis S, Sinclair I (2000) Numerical modelling of combined roughness and plasticity induced crack closure effects in fatigue. Materials Science and Engineering a-Structural Materials Properties Microstructure and Processing. 291: 224-234.

47. Park SJ, Song JH (1999) Simulation of fatigue crack closure behavior under variable-amplitude loading by a $2 \mathrm{D}$ finite element analysis based on the most appropriate mesh size concept. American Society of Testing Materials, 337348.

48. Heper R, Vardar O (2003) Elastic-plastic material response of fatigue crack surface profiles due to overload interactions. International Journal of Fatigue. 25: $801-810$.

49. Lalor P, Sehitoglu H (1988) Fatigue crack closure outside small scale yielding regime. Mechanics of Fatigue Crack Closure. American Society of Testing Materials, 342-360.

50. McClung RC (1988) Fatigue crack closure and crack growth outside the small scale yielding regime. University of Illinois and Urbana-Champaign.

51. McClung RC (1989) Application of a finite element analysis on fatigue crack closure. 7th International Conference of Fracture.

52. Schijve J (2008) Fatigue of Structures and Materials. Springer Netherlands.

53. Nowell D, Paynter RJH, De Matos PFP (2010) Optical methods for measurement of fatigue crack closure: moire interferometry and digital image correlation. Fatigue \& Fracture of Engineering Materials \& Structures. 33: 778-790.

54. Yates JR, Zanganeh M, Tai YH (2010) Quantifying crack tip displacement fields with DIC. Engineering Fracture Mechanics. 77: 2063-2076.

55. Paris P, Erdogan F (1963) A critical analysis of crack propagation rules. Journal of Basic Engineering. 85: 528-534.

56. Elber W (1970) Fatigue crack closure under cyclic tension. Engineering Fracture Mechanics. 2: 37-45. 


\section{List of Figures}

Fig 1. Position of loading points and notch detail.

Fig 2. Half model showing FE boundary conditions.

Fig 3. Plastic zone regions for a fatigue crack.

Fig 4. Reversed plastic zone size (also called cyclic plastic zone) $)^{39}$.

Fig 5. Mesh reduction scheme with combination of normal handmade reduction and MPC.

Fig 6. Plastic zone ahead of the crack, and the larger K-field that must exist for LEFM to be applicable ${ }^{26}$.

Fig 7. Plastic zone size under monotonic load for plane stress, Irwin's approximation.

Fig 8. Specimen geometry.

Fig 9. Crack path comparisons among real and numerical cases.

Fig 10. Comparison for a) opening and b) closure values for constant amplitude loading using different element sizes.

Fig 11. Plastic zone size $r_{p}$.

Fig 12. Reversed plastic zone size $r_{y}$.

Fig 13. Opening and closure stresses measured for node release every cycle and every other cycle.

Fig 14. Analysis of time increments on numerical a) opening and b) closure values for constant amplitude loading $\left(\mathrm{M}=1.25 \mathrm{~mm}, \sigma_{\max }=0.29 \sigma_{\mathrm{y}}\right)$.

Fig 15. Constant amplitude crack growth rate data versus crack length.

List of Tables

Table 1 Number of elements yielded in front of crack tip, $M=1.25, \sigma \max / \sigma y=0.3$, $\mathrm{R}=0$

Table 2 Number of elements within the monotonic plastic zone $\left(r_{p}\right)$, element size $\Delta a=0.00390625 \mathrm{~mm}$. 


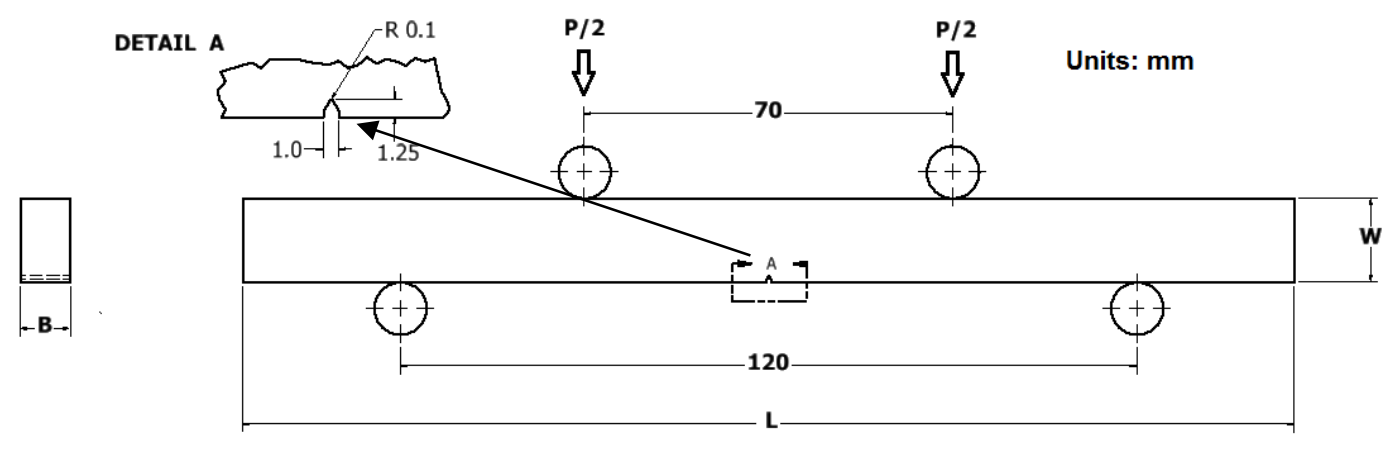

Fig 1. Position of loading points and notch detail. 


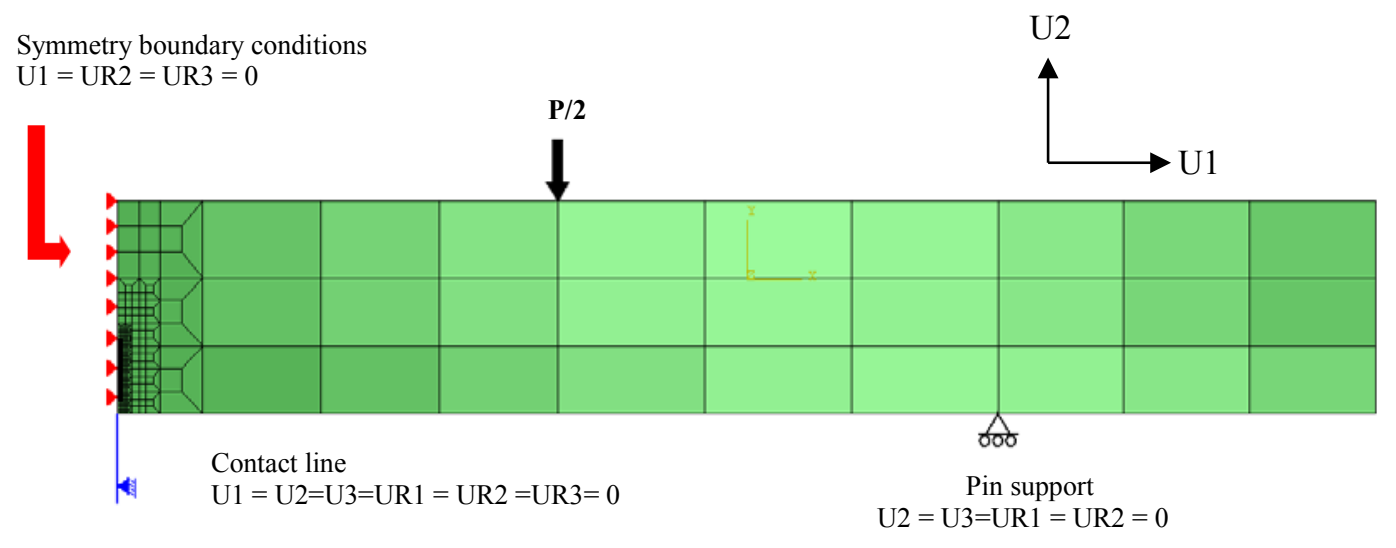

Fig 2. 2D half model showing FE boundary conditions. 


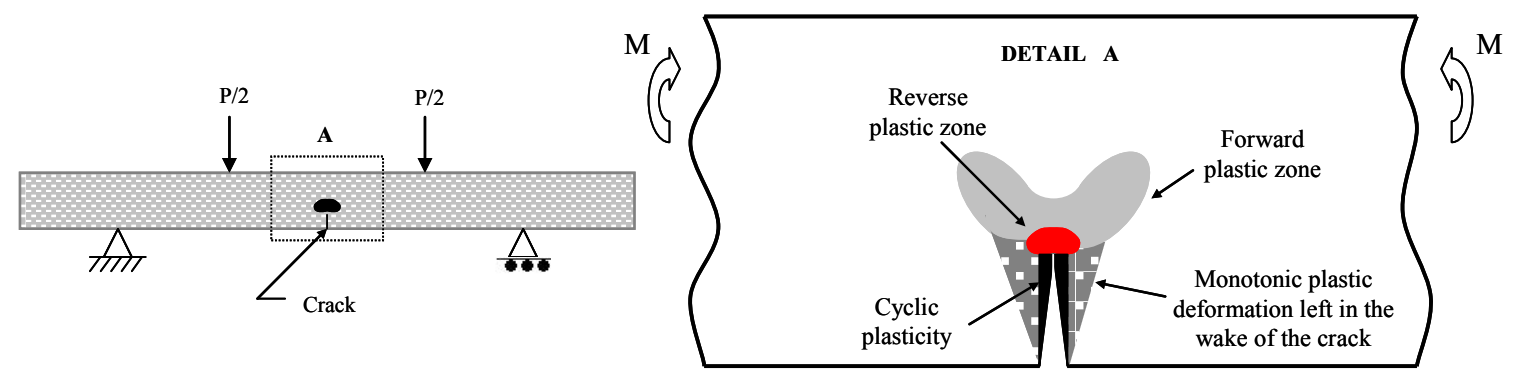

Fig 3. Plastic zone regions for a fatigue crack. 


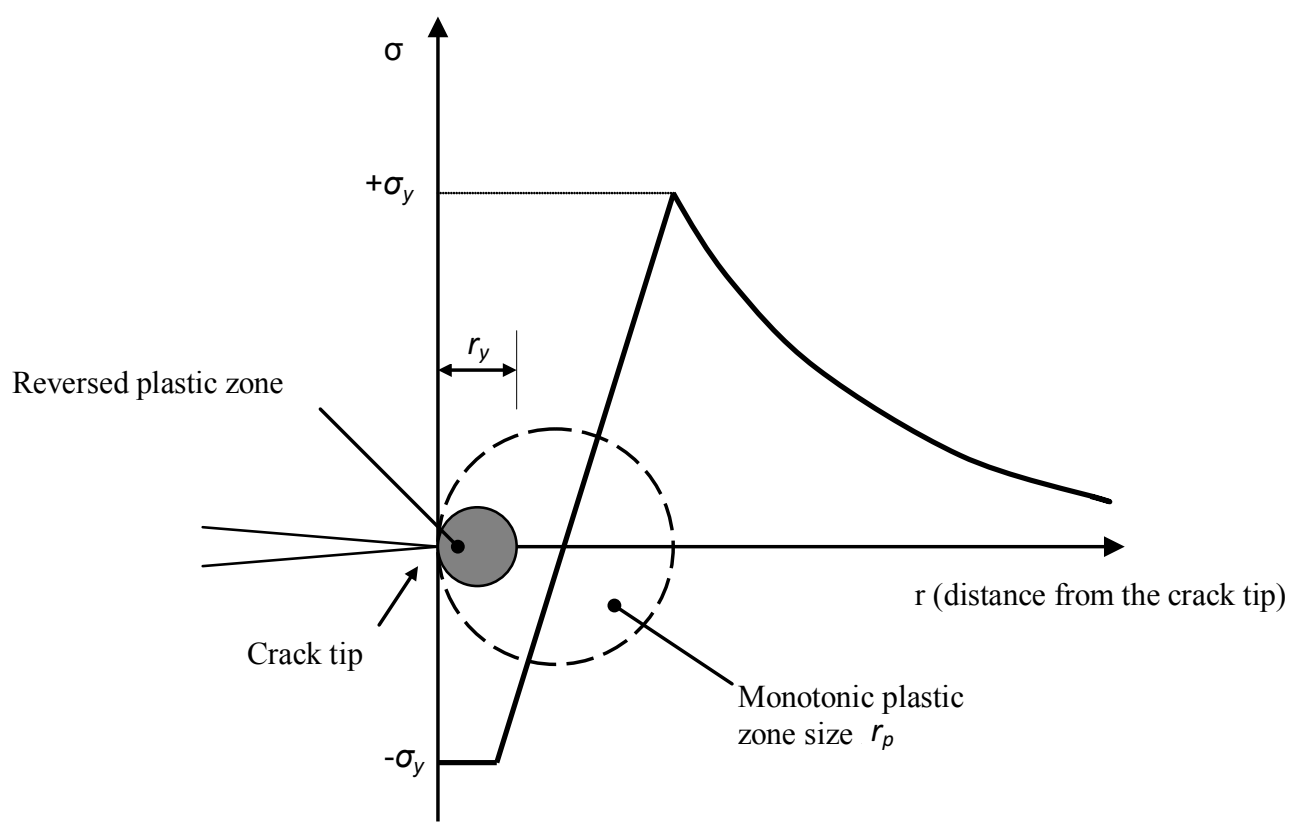

Fig 4. Reversed plastic zone size (also called cyclic plastic zone) ${ }^{39}$. 


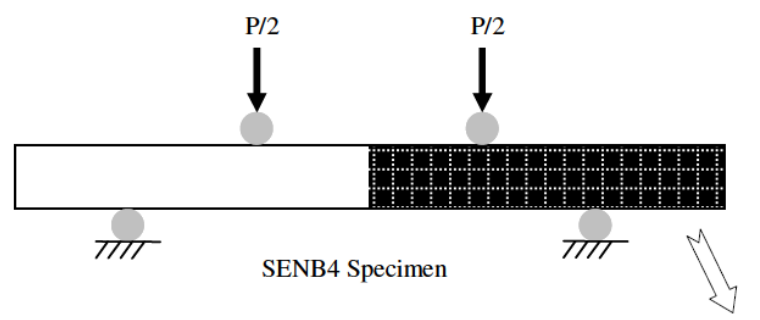

Mesh scheme using simple hand 1:3 reduction and MPC to optimize mesh for a half four point specimen. $3.9 \mu \mathrm{m}$ minimum element size 12,871 elements for $1587.5 \mathrm{~mm}^{2}$

Multipoint constraint (MPC) between slave and master surfaces along the contact line

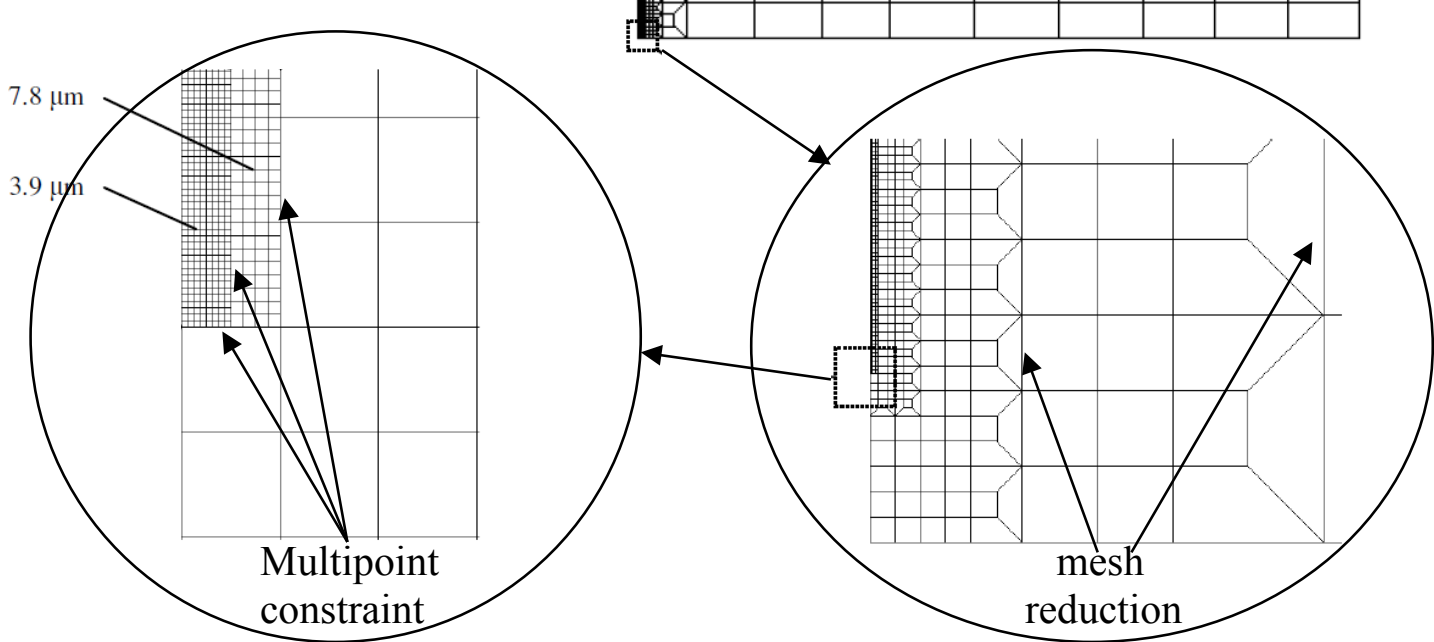

Fig 5. Mesh reduction scheme with combination of normal handmade reduction and MPC. 


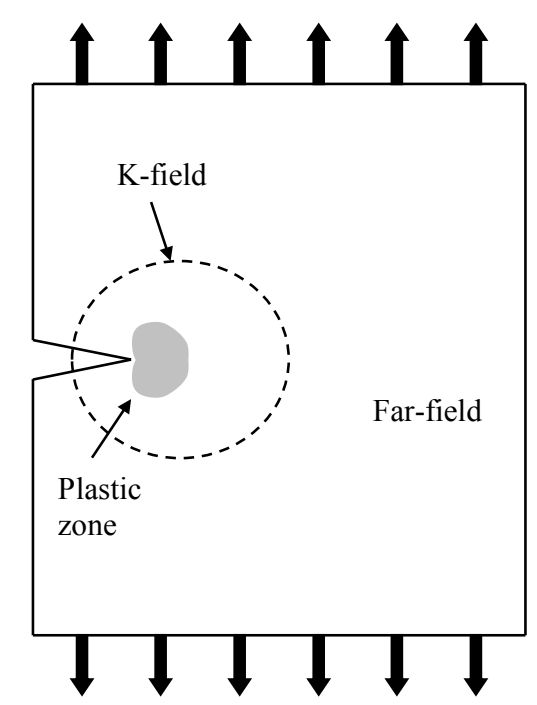

Fig 6. Plastic zone ahead of the crack, and the larger $K$-field that must exist for LEFM to be applicable ${ }^{26}$. 


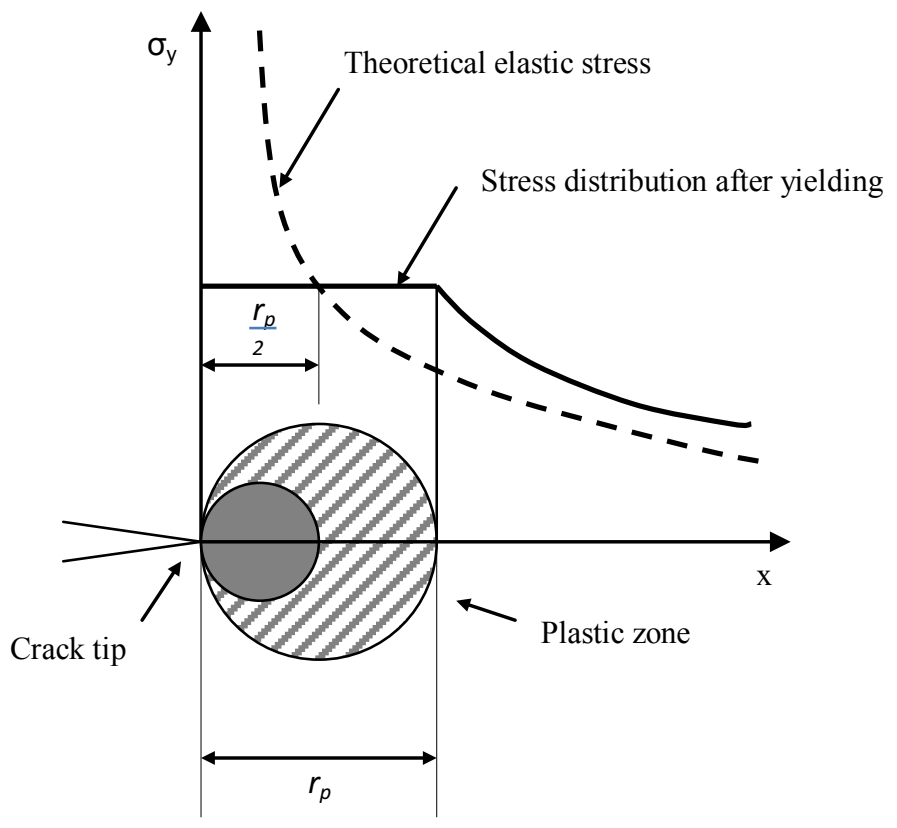

Fig 7. Plastic zone size under monotonic load for plane stress, Irwin's approximation. 

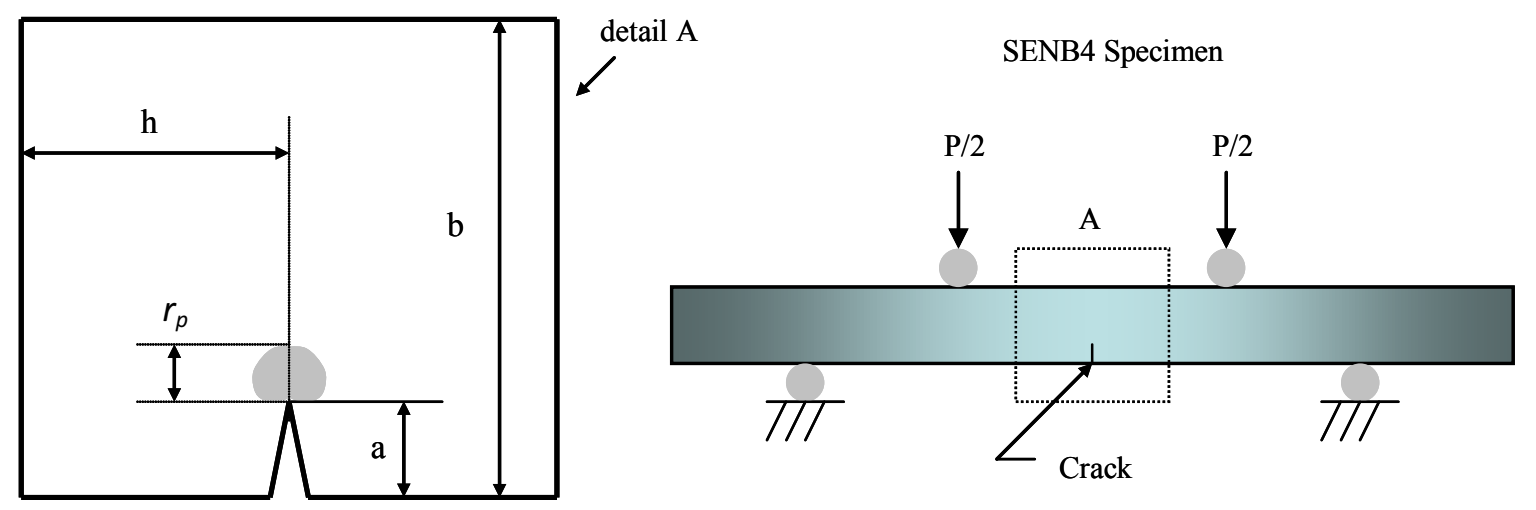

Fig 8. Specimen geometry. 


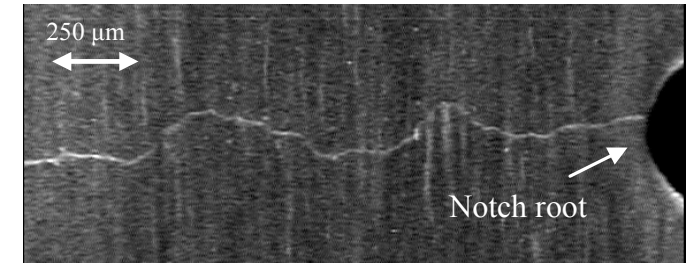

a) $2 \mathrm{~mm}$ crack length

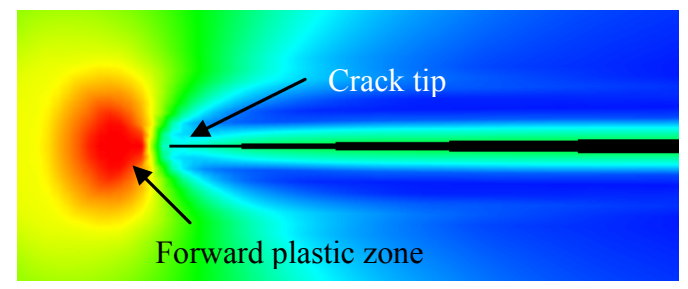

c) Von Misses yield criteria

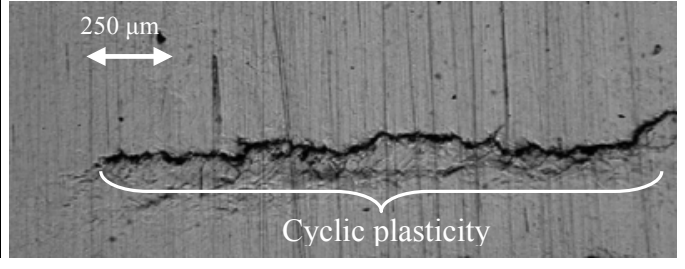

b) End of a $4 \mathrm{~mm}$ crack length

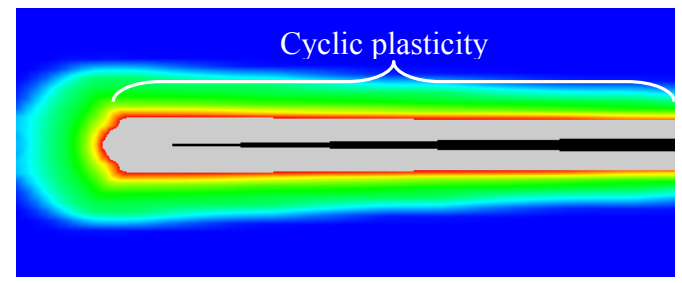

d) Plastic strain magnitude

Fig 9. Crack path comparisons among real and numerical cases. 
a)

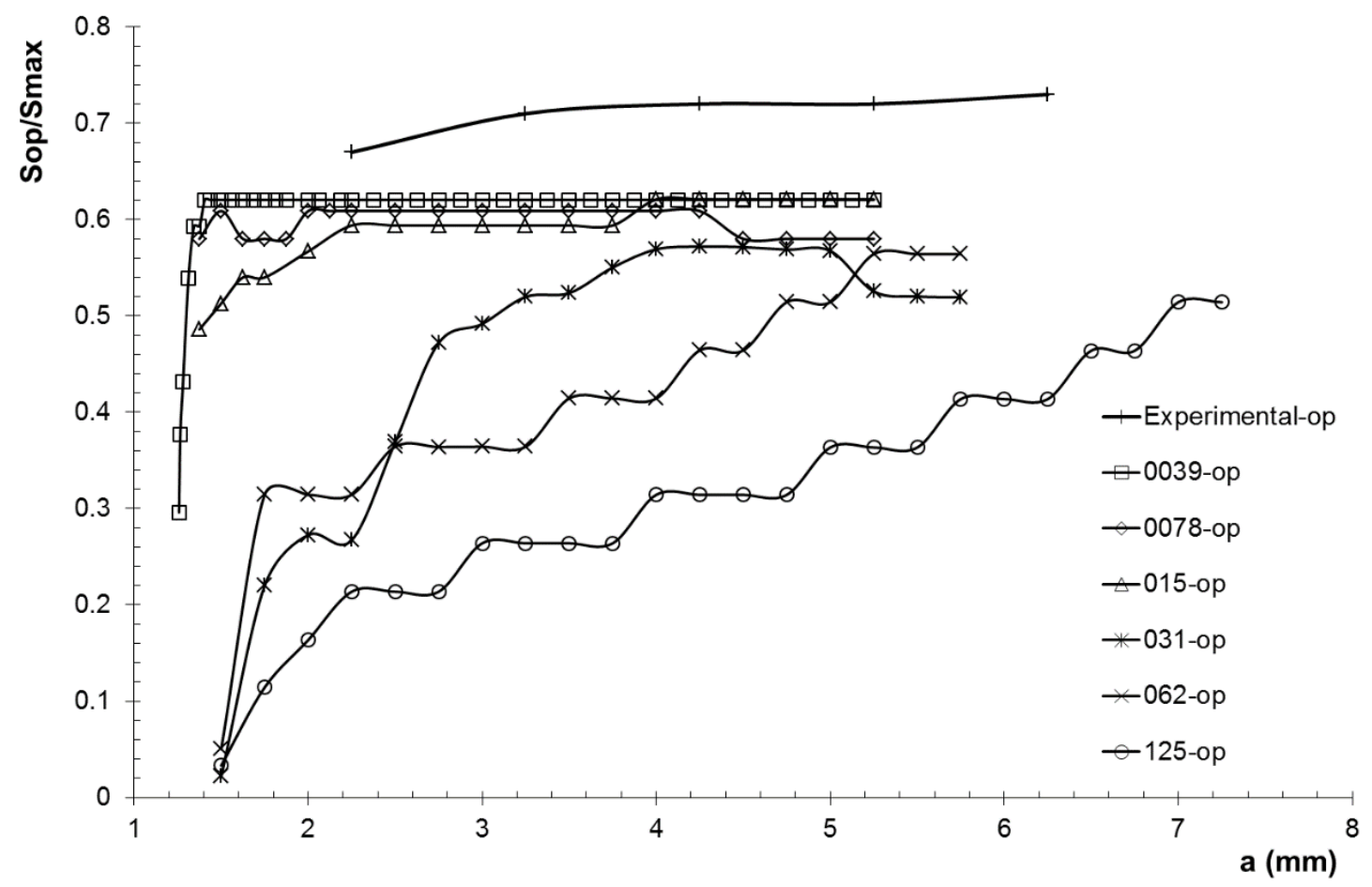

b)

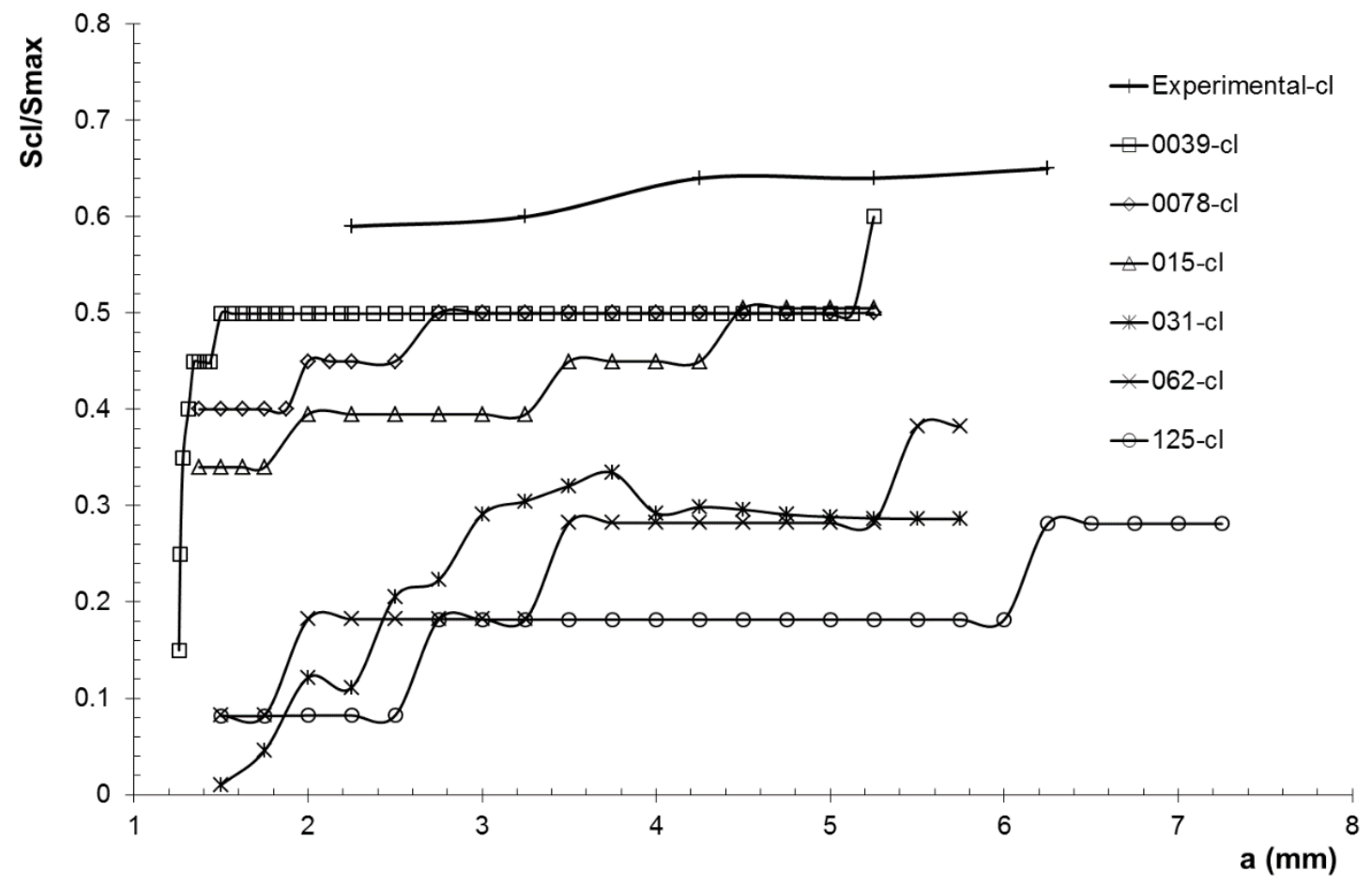

Fig 10. Comparison for a) opening and b) closure values for constant amplitude loading using different element sizes. 


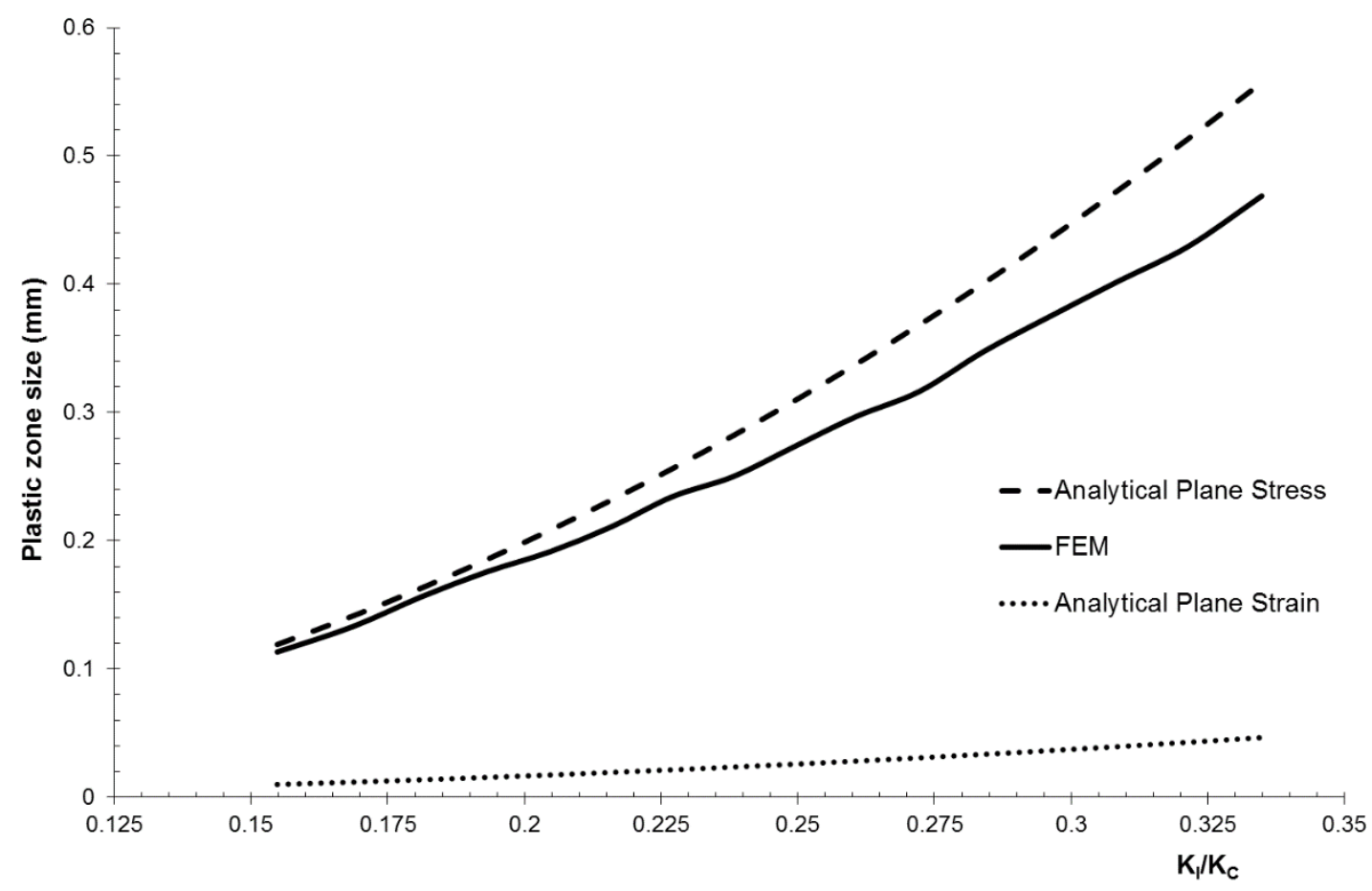

Fig 11. Plastic zone size $r_{p}$. 


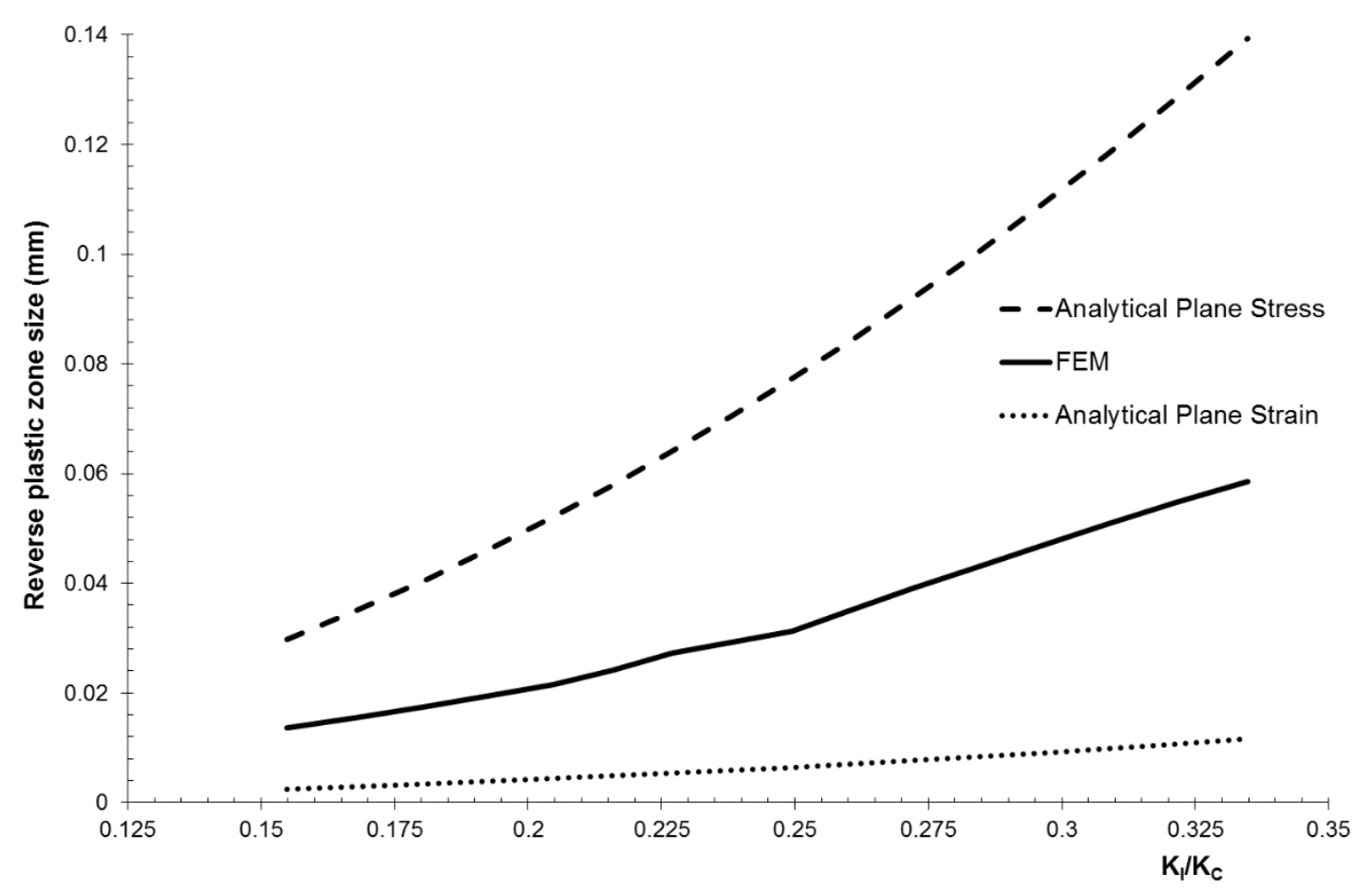

Fig 12. Reversed plastic zone size $r_{y}$. 


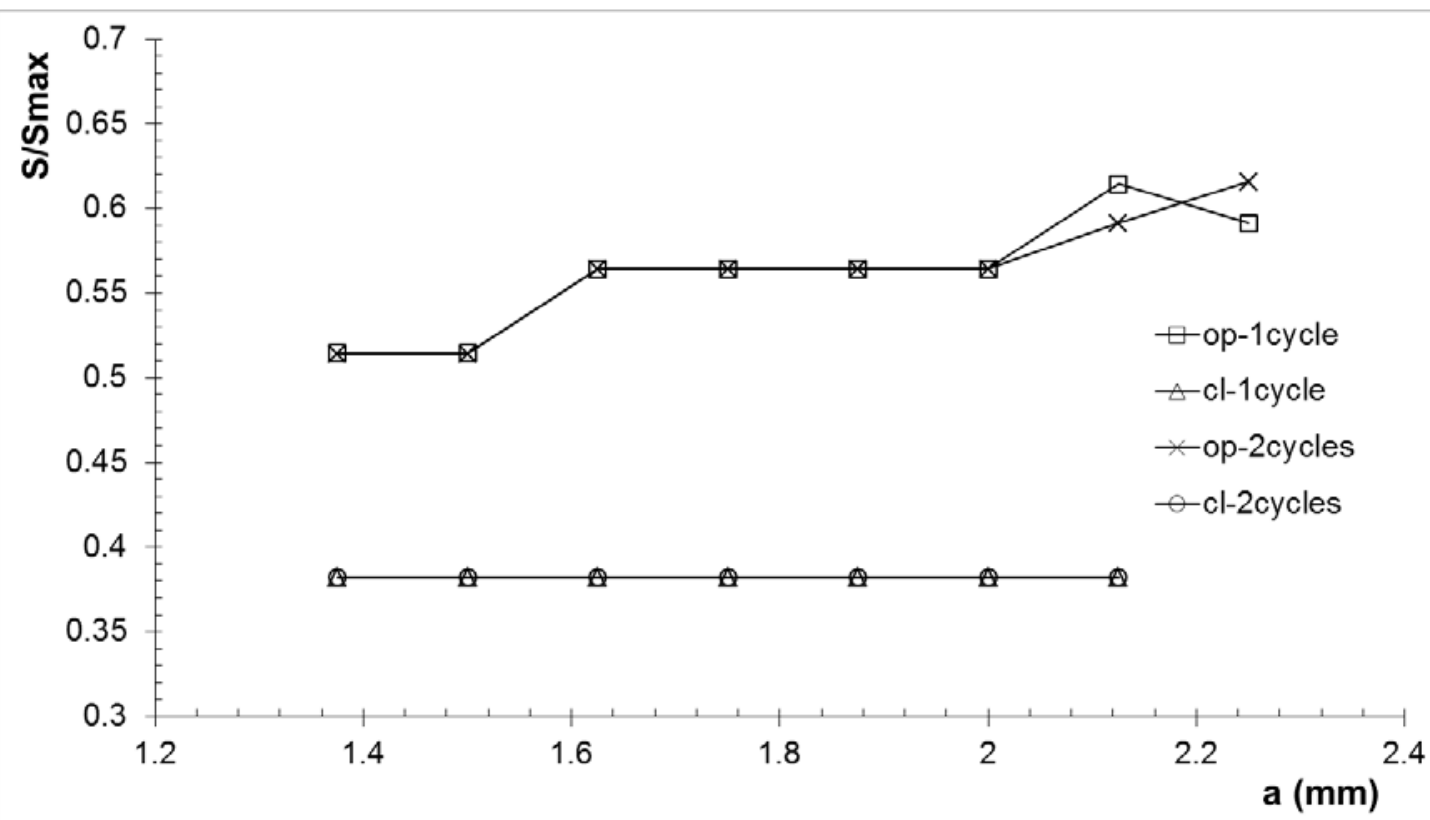

Fig 13. Opening and closure stresses measured for node release every cycle and every other cycle. 
a)

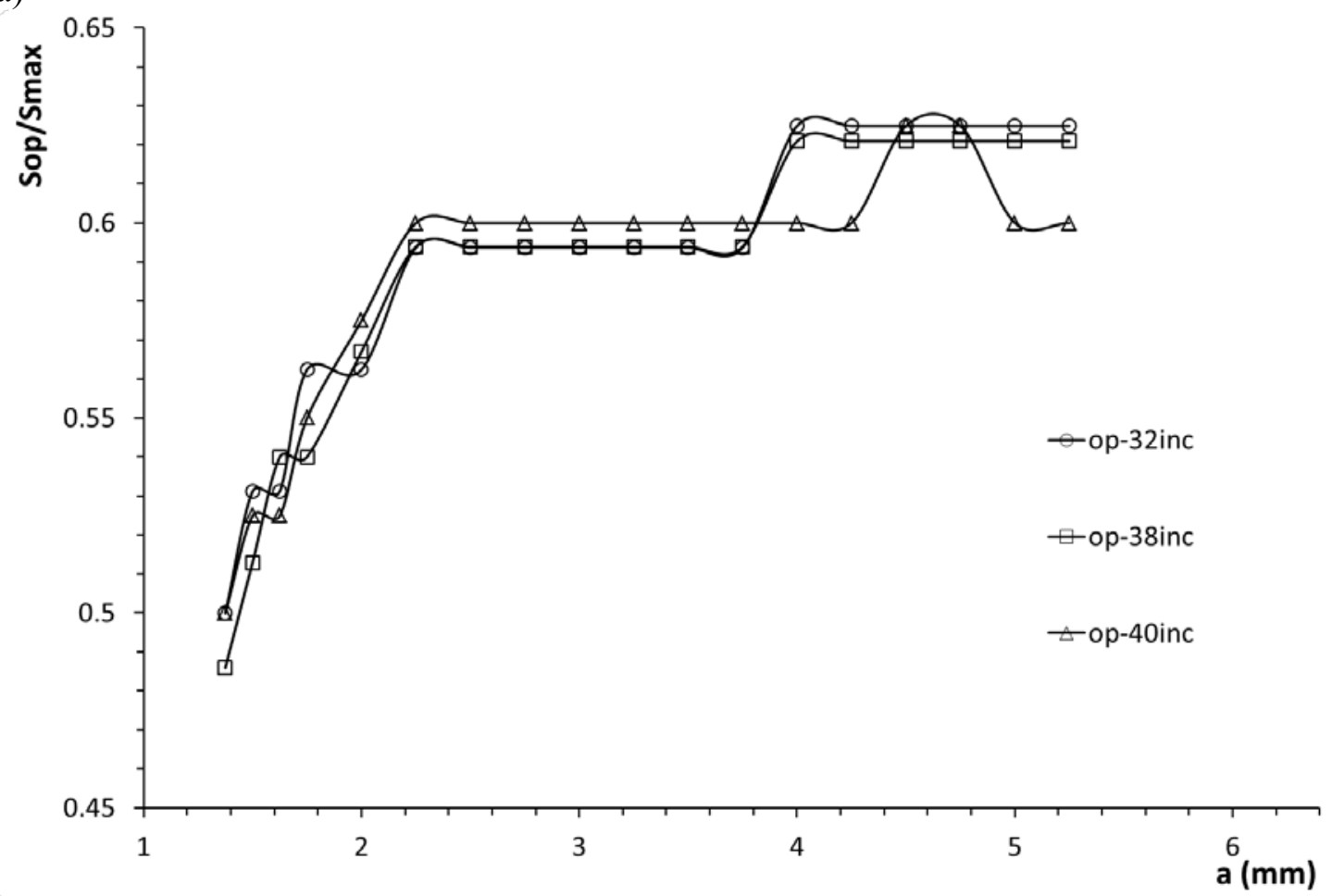

b)

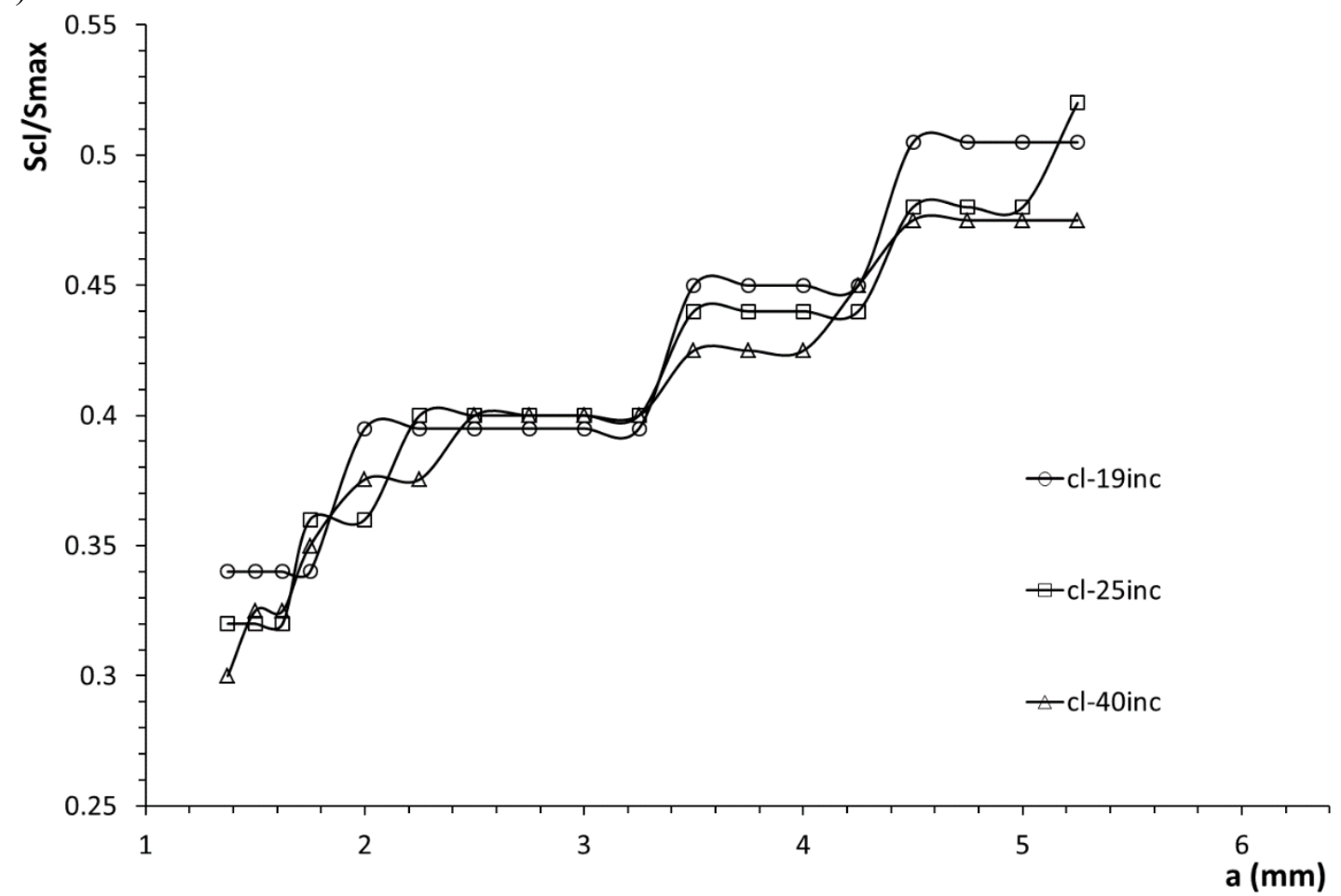

Fig 14. Analysis of time increments on numerical a) opening and b) closure values for constant amplitude loading $\left(\mathrm{M}=1.25 \mathrm{~mm}, \sigma_{\max }=0.29 \sigma_{\mathrm{y}}\right)$. 


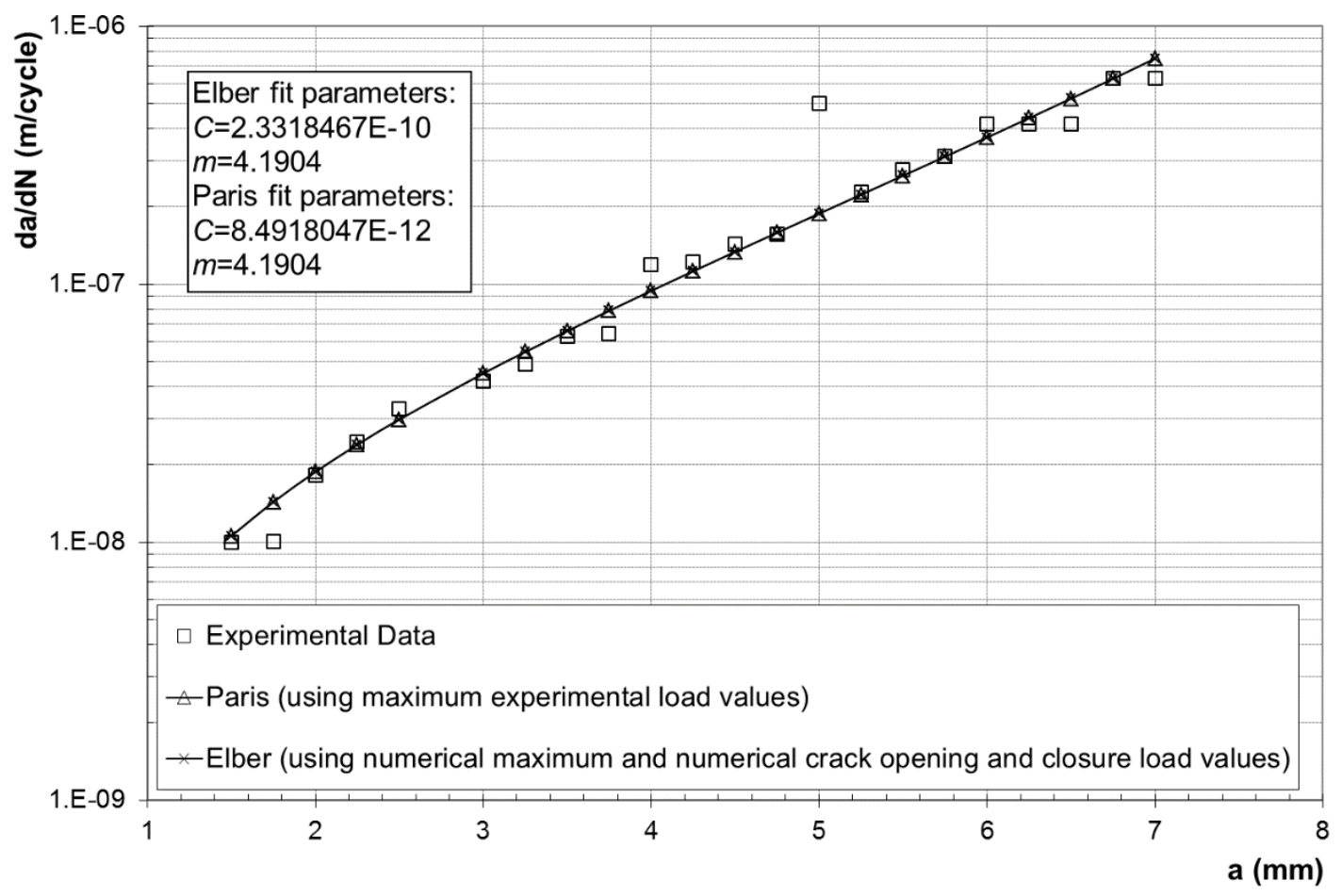

Fig 15. Constant amplitude crack growth rate data versus crack length. 
Table 1

Number of elements yielded in front of crack tip, $\mathrm{M}=1.25, \sigma_{\max } / \sigma_{y}=0.3, R=0$

\begin{tabular}{|c|c|c|c|c|c|c|c|}
\hline \multirow{2}{*}{$\begin{array}{c}\mathrm{a} \\
\mathrm{mm}\end{array}$} & \multirow{2}{*}{$\begin{array}{c}r_{p}=\frac{1}{\pi}\left(\frac{K_{I}}{\sigma_{y}}\right)^{2} \\
\text { forward plastic } \\
\begin{array}{c}\text { zone } \\
\mathrm{mm}\end{array}\end{array}$} & \multicolumn{6}{|c|}{$\begin{array}{l}\text { Element size of the mesh employed } \\
\text { in simulation }\end{array}$} \\
\hline & & $\begin{array}{l}125 \\
\mu \mathrm{m}\end{array}$ & $\begin{array}{l}62.5 \\
\mu \mathrm{m}\end{array}$ & $\begin{array}{l}31.1 \\
\mu \mathrm{m}\end{array}$ & $\begin{array}{l}15.6 \\
\mu \mathrm{m}\end{array}$ & $\begin{array}{l}7.8 \\
\mu \mathrm{m}\end{array}$ & $\begin{array}{l}3.9 \\
\mu \mathrm{m}\end{array}$ \\
\hline 1.75 & 0.1622 & 1 & 1 & 2 & 8 & 17 & 33 \\
\hline 2.25 & 0.2071 & 1 & 2 & 5 & 10 & 21 & 42 \\
\hline 2.75 & 0.255 & 1 & 3 & 6 & 12 & 25 & 50 \\
\hline 3.25 & 0.3075 & 1 & 3 & 7 & 15 & 30 & 61 \\
\hline 3.75 & 0.3665 & 2 & 4 & 8 & 18 & 36 & 71 \\
\hline 4.25 & 0.4338 & 2 & 5 & 10 & 21 & 42 & 83 \\
\hline 4.75 & 0.5112 & 3 & 6 & 12 & 24 & 48 & 97 \\
\hline 5.25 & 0.6012 & 3 & 7 & 14 & 27 & 55 & 112 \\
\hline
\end{tabular}


Table 2

Number of elements within the monotonic plastic zone $\left(r_{p}\right)$, element size $\Delta a=0.00390625$ $\mathrm{mm}$.

\begin{tabular}{|c|c|c|c|c|}
\hline $\begin{array}{l}\text { Crack } \\
\text { length } \\
(\mathrm{mm})\end{array}$ & $\begin{array}{l}\text { Plastic zone } \\
\text { size }(\mathrm{mm}) \\
\text { analytical } \\
\end{array}$ & $\begin{array}{l}\text { Number } \\
\text { of } \\
\text { elements }\end{array}$ & $\begin{array}{c}\text { Plastic zone } \\
\text { size (mm) } \\
\text { ABAQUS }\end{array}$ & $\begin{array}{l}\text { McClung } \\
\text { (1989) } \\
\text { criterion }\end{array}$ \\
\hline $\mathrm{a}$ & $r_{p}$ & at $K_{\max }$ & $r_{p}$ & $\Delta a / r_{p} \leq 0.1$ \\
\hline 1.25 & 0.119078 & 29 & 0.113281 & 0.034483 \\
\hline 1.5 & 0.141061 & 34 & 0.132813 & 0.029412 \\
\hline 1.75 & 0.163071 & 40 & 0.15625 & 0.025 \\
\hline 2 & 0.18536 & 45 & 0.175781 & 0.022222 \\
\hline 2.25 & 0.208166 & 49 & 0.191406 & 0.020408 \\
\hline 2.5 & 0.231721 & 54 & 0.210938 & 0.018519 \\
\hline 2.75 & 0.256247 & 60 & 0.234375 & 0.016667 \\
\hline 3 & 0.281962 & 64 & 0.25 & 0.015625 \\
\hline 3.25 & 0.309078 & 70 & 0.273438 & 0.014286 \\
\hline 3.5 & 0.337811 & 76 & 0.296875 & 0.013158 \\
\hline 3.75 & 0.368376 & 81 & 0.316406 & 0.012346 \\
\hline 4 & 0.400998 & 89 & 0.347656 & 0.011236 \\
\hline 4.25 & 0.435916 & 96 & 0.375 & 0.010417 \\
\hline 4.5 & 0.473385 & 103 & 0.402344 & 0.009709 \\
\hline 4.75 & 0.513689 & 110 & 0.429688 & 0.009091 \\
\hline 5 & 0.557146 & 120 & 0.46875 & 0.008333 \\
\hline 5.25 & 0.604121 & 128 & 0.5 & 0.007813 \\
\hline
\end{tabular}

